Article

\title{
Viscosity, Degree of Polymerization, Water Uptake, and Water Solubility Studies on Experimental Dichloro-BisGMA-Based Dental Composites
}

\author{
Abdel-Basit Al-Odayni ${ }^{1, *(D)}$, Waseem Sharaf Saeed ${ }^{1}\left(\mathbb{D}\right.$, Rawaiz Khan ${ }^{1}$, Abdullah Al-Kahtani ${ }^{2}$ (D) Taieb Aouak $^{2}$, \\ Khalid Almutairi ${ }^{3}$ and Ali Alrahlah ${ }^{1,4}{ }^{\mathbb{D}}$ \\ 1 Engineer Abdullah Bugshan Research Chair for Dental and Oral Rehabilitation, College of Dentistry, \\ King Saud University, Riyadh 11545, Saudi Arabia; wsaeed@ksu.edu.sa (W.S.S.); krawaiz@ksu.edu.sa (R.K.); \\ aalrahlah@ksu.edu.sa (A.A.) \\ 2 Chemistry Department, College of Science, King Saud University, P.O. Box 2455, Riyadh 11451, Saudi Arabia \\ akahtani@ksu.edu.sa (A.A.-K.); taouak@ksu.edu.sa (T.A.) \\ 3 Maxillofacial Surgery Department, King Saud Medical City, Ministry of Health, Riyadh 12746, Saudi Arabia; \\ kmutairi@ksmc.med.sa \\ 4 Restorative Dental Sciences Department, College of Dentistry, King Saud University, \\ Riyadh 11545, Saudi Arabia \\ * Correspondence: aalodayni@ksu.edu.sa
}

check for updates

Citation: Al-Odayni, A.-B.; Saeed, W.S.; Khan, R.; Al-Kahtani, A.; Aouak, T.; Almutairi, K.; Alrahlah, A Viscosity, Degree of Polymerization, Water Uptake, and Water Solubility Studies on Experimental Dichloro-BisGMA-Based Dental Composites. Appl. Sci. 2021, 11, 3577. https://doi.org/10.3390/app11083577

Academic Editor: Bruno Chrcanovic

Received: 29 March 2021

Accepted: 14 April 2021

Published: 16 April 2021

Publisher's Note: MDPI stays neutral with regard to jurisdictional claims in published maps and institutional affiliations.

Copyright: (C) 2021 by the authors Licensee MDPI, Basel, Switzerland. This article is an open access article distributed under the terms and conditions of the Creative Commons Attribution (CC BY) license (https:// creativecommons.org/licenses/by/ $4.0 /)$
Abstract: The objective of this work was to investigate the advantages of using dichloro bisphenol A-glycidyl methacrylate (dCl-BisGMA) as a potential matrix for dental resin composites. A series of model composites containing $65 \mathrm{wt} \%$ resin (urethane dimethacrylate/triethylene glycol dimethacrylate/BisGMA as 1:3:1) and $35 \mathrm{wt} \%$ silanated silica were prepared. Thus, BisGMA was replaced by dCl-BisGMA as 0, 25, 50, and $100 \mathrm{wt} \%$ to obtain UTBC0, UTBC25, UTBC50, and UTBC100, respectively. The composites' rheological properties, degree of double-bond conversion (DC), water sorption $\left(\mathrm{W}_{\mathrm{SP}}\right)$, and water solubility $\left(\mathrm{W}_{\mathrm{SL}}\right)$ were examined. The data revealed a statistically significant reduction in the complex viscosity of composites containing dCl-BisGMA, compared with UTBC0. No significant differences between DCs were detected $(p<0.05)$. A significant enhancement in the reduction of the $\mathrm{dCl}$-BisGMA composite $\mathrm{W}_{\mathrm{SP}}$ was also detected, and conversely, $\mathrm{W}_{\mathrm{SL}}$ was increased. Although the viscosity, DC, and $W_{\mathrm{SP}}$ characters were enhanced, a $\mathrm{W}_{\mathrm{SL}}$ increase is an undesirable development. However, $\mathrm{W}_{\mathrm{SL}}$ is supposedly caused by cyclization of small flexible chains, which is more likely to occur in the presence of hydrophobic monomers such as dCl-BisGMA and more prone to leaching than are crosslinked networks. We concluded that dCl-BisGMA is a monomer that could potentially be used as an alternative or in combination with traditional monomers, including BisGMA, in resin-based dental composites, and it deserves further investigation.

Keywords: dichloro-BisGMA; resin matrix; dental composite; degree of conversion; water uptake; water solubility

\section{Introduction}

Since the early 1960s, 2,2-bis[p-(20-hydroxy-30-methacryloxypropoxy) phenyl] propane, known as bisphenol A glycidyl methacrylate (BisGMA) or "Bowen's resin," has been the most widely used resin in the field of resin-based dental materials, including restorative composites, adhesives, and prophylactic sealants. Structurally, BisGMA has a high molecular weight of $512.6 \mathrm{~g} / \mathrm{mol}$ with two terminal methacrylate functionalities, a stiff central core of two phenyl rings, and two hydroxyl groups. Such a structure facilitates a strong intermolecular interaction through hydrogen bonding and $\pi-\pi$ interactions, leading to the extremely high viscosity of the monomer (910 Pa.s) [1,2]. The advantage of using BisGMA in dental composites is its low volatility and diffusivity into tissues (i.e., lesser toxicity), low volumetric shrinkage, rapid hardening, and aesthetic properties [3]. However, its high 
viscosity raises handling issues, decreases the degree of vinyl double-bond conversion (DC) upon curing, and restricts the addition of an adequate amount of reinforcing materials required for better mechanical properties of the restoratives [1,4]. To deal with viscosity issues, the incorporation of reactive, low-viscosity dimethacrylate monomers (diluents) within the resin matrices of dental composites is necessary. The most commonly used diluent is triethylene glycol dimethacrylate (TEGDMA); however, some other dimethacrylates, including ethoxylated bisphenol A dimethacrylate (BisEMA), urethane dimethacrylate (UDMA), and ethylene glycol dimethacrylate (EGDMA), are used in combination with BisGMA [4]. Owing to the linear structure associated with triethylene oxide spacers, the addition of TEGDMA commonly enhances the hydrophilicity characteristics of the resins and increases water sorption and microcavities, which further affect the longevity of the composites.

Indeed, the viscosity issue of BisGMA necessitates material development; thus, BisGMA structural modification including the replacement of its $\mathrm{OH}$ groups with low hydrophilic substituents may be one solution. In this context, various derivatives of BisGMA have been synthesized by different researchers, in which the $\mathrm{OH}$ functional groups were partially or fully replaced with targeted substituents, including alkyls, aryls, ethers, and esters with small or bulky groups [3,5-12]. Regardless of the type of substituent used, the viscosity of BisGMA was greatly reduced after modification, confirming that $\mathrm{H}$-bonding is the major cause of its high viscosity character $[2,6,10,12,13]$. Adversely, substitution may affect the hygroscopic, mechanical, DC, and some other critical physicochemical properties of the composites. For example, modification of the BisGMA structure with less hydrophilic, small-sized substituents, such as methyl [14], methoxy [6], and chloride [2], resulted in low viscous analogs $\left(\eta=8.4,3.6\right.$, and $7.2 \mathrm{~Pa} \cdot \mathrm{s}$, respectively, at $\left.\sim 22-25^{\circ} \mathrm{C}\right)$. The incorporation of modified-BisGMA resin in dental composites showed enhanced properties, e.g., lower volumetric shrinkage, better mechanical properties, and lower water uptake [6,14]. However, regulation of the degree of $\mathrm{OH}$ substitution may result in tailored properties [8], e.g., when diluents were not used.

Recently, Al-Odayni et al. synthesized a chlorinated analog of BisGMA (dichloroBisGMA; termed dCl-BisGMA) with lower viscosity (7.22 Pa-s), compared with that of BisGMA (910 Pa.s) [2]. Then, dCl-BisGMA was incorporated within unfilled resins, and its properties, including $\mathrm{DC}$, water sorption $\left(\mathrm{W}_{\mathrm{SP}}\right)$, water solubility $\left(\mathrm{W}_{\mathrm{SL}}\right)$, and biocompatibility were evaluated. A structural modification of BisGMA with one chlorine (termed mCl-BisGMA) was also synthesized with a viscosity value of $8.3 \mathrm{~Pa} \cdot \mathrm{s}$ at $25^{\circ} \mathrm{C}$ [15]. The substantial reduction in the viscosity values of $\mathrm{mCl}$ - and dCl-BisGMA (about 65- and 126fold, respectively, lower than BisGMA) may indicate their potential use as alternatives for BisGMA in the dental resin matrix. The overall remarkable enhancements in the BisGMA properties after modification with mono- $\mathrm{Cl}$ and di-Cl are of great importance in the field of dental materials and thus deserve further investigation, e.g., to explore its potential as a resin matrix for filled resin-based dental composites.

The aim of this study was to investigate the effect of replacing BisGMA by dCl-BisGMA on the properties (rheological, DC, $\mathrm{W}_{\mathrm{SP}}$, and $\mathrm{W}_{\mathrm{SL}}$ ) of experimental dental composites. Therefore, a series of dental composites containing UDMA, TEGDMA, and BisGMA/dClBisGMA as the base resin ( $35 \mathrm{wt} \%$ ) and organic fillers (silanated Aerosil fumed silica, SA200) were prepared, in which the amount of BisGMA was gradually replaced by dCl-BisGMA.

\section{Materials and Methods}

\subsection{Materials}

The monomeric materials BisGMA ( $>98 \%)$, TEGDMA ( $>95 \%)$, and UDMA $(>97 \%)$, as well as the photoinitiator camphorquinone (CQ; $97 \%)$, the curing accelerator 2-(N,Ndimethylamino)ethyl methacrylate (DMAEMA; 98\%), the coupling agent $\gamma$ methacryloxypropyltrimethoxysilane ( $\gamma$-MPS; $98 \%$ ), and the chlorine source carbon tetrachloride $\left(\mathrm{CCl}_{4} ;>99.8 \%\right)$, were purchased from Sigma-Aldrich (Taufkirchen, Germany). Appel reaction catalyst triphenylphosphine $\left(\mathrm{Ph}_{3} \mathrm{P} ;>98 \%\right)$ was obtained from Cica-Reagent 
(Kanto Chemical, Tokyo, Japan). The solvents $n$-hexane $(n-\mathrm{H} ;>97 \%)$, ethyl acetate (EA; 99\%), and dichloromethane (DCM; 99.6\%) were procured by Fisher Scientific (Loughborough, UK). Th model filler Aerosil-200 fumed silica (A200) was purchased from Evonik (Evonik Industries, Essen, Germany) and was modified with $\gamma$-MPS. All chemicals were used as received unless stated otherwise.

\subsection{Methods}

\subsubsection{Synthesis of dCl-BisGMA}

dCl-BisGMA was synthesized using a previously described method [2] with slight modification. Thus, a solution of BisGMA in DCM $(0.3 \mathrm{~g} / \mathrm{mL})$ was prepared with stirring and purged for $10 \mathrm{~min}$ with $\mathrm{N}_{2}$ gas. To this solution, an equimolar amount of $\mathrm{CCl}_{4}$ ( $0.039 \mathrm{~mol})$ was added and homogenized with stirring for $15 \mathrm{~min}$, and thereafter, $18 \mathrm{~g}$ of the catalyst $\mathrm{Ph}_{3} \mathrm{P}$ was added. The reaction was refluxed for $2 \mathrm{~h}$ and cooled to room temperature, and then to facilitate precipitation of the $\mathrm{Ph}_{3} \mathrm{P}$-oxide by product, an adequate amount of an $\mathrm{EA} / n-\mathrm{H}(1: 1 v / v)$ solvent mixture was added and left to settle in a dark environment overnight. Then, the supernatant was decanted, and the solvent was reduced using a rotary evaporator at $30^{\circ} \mathrm{C}$. The obtained product was purified as described elsewhere [2]. After purification, a low viscosity, light-yellow resin with an isolated yield of $64 \%$ was achieved, which was kept in a dark container at about $8^{\circ} \mathrm{C}$ until use.

\subsubsection{Modification of Silica Nanoparticles}

The hydrophilic, amorphous fumed silica (A200) with an average particle size of $12 \mathrm{~nm}, 200 \pm 25 \mathrm{~m}^{2} / \mathrm{g}$ Brunauer-Emmett-Teller (BET) specific surface area, $\leq 1.5$ mass loss on drying, and 3.7-4.5 pH [16] was modified with $10 \mathrm{wt} \%$ of organosilane ( $\gamma$-MPS), following previously described methods [16-19]. A200 is a commercially available, lowcost, and modifiable silica, with applicable properties for use in dental composites [20]. Owing to its high surface area, 35\% was the highest applicable load. However, nanofillers typically need a high amount of resins for complete surface wetting.

\subsubsection{Preparation of Resin Composites}

A series of dental resin composites containing $65 \mathrm{wt} \%$ organic-based matrix (of which $20 \mathrm{wt} \%$ is BisGMA) and $35 \mathrm{wt} \%$ inorganic fillers were prepared. The amount of BisGMA in the composite was replaced sequentially with $0,25,50$, and $100 \mathrm{wt} \%$ dCl-BisGMA (denoted as UTBCx, in which $\mathrm{x}$ is the amount (\%) of $\mathrm{dCl}$-BisGMA with respect to the total BisGMA and dCl-BisGMA), as shown in Table 1. Composites were prepared as follows: the UDMA/TEGDMA blend was first prepared, and then the predetermined amounts of BisGMA and dCl-BisGMA were added. The initiator was completely dissolved in the monomer mixture before the addition of the SA200 filler. Next, composites were manually homogenized using a stainless-steel spatula, sonicated for $3 \mathrm{~min}$, and degassed under reduced pressure for $10 \mathrm{~min}$. Then, the composites were mechanically mixed, three times at $3000 \mathrm{rpm}$ for $1 \mathrm{~min}$ each with $2 \mathrm{~min}$ rest in between, in a dual asymmetric centrifugal mixing system (Speed Mixer TM DAC 150 FVZ; Hauschild \&Co., Hamm, Germany). To assure similar conditions, one batch of each resin was prepared and subsequently used throughout all the experiments.

\subsection{Analytical Experiments \\ 2.3.1. Rheological Test}

The rheological properties of the UTBC model composites were measured on an MCR 72 rheometer (Anton Paar, Graz, Austria) using a $25 \mathrm{~mm}$ diameter parallel-plate geometry and a measuring gap of $0.25 \mathrm{~mm}$. The experimental test was performed at the oscillatory shear mode over a frequency sweep range of 0.1 to $100(\omega, \mathrm{rad} / \mathrm{s})$ at $25{ }^{\circ} \mathrm{C}$. At least four replicate measurements $(n=4)$ were made per sample and averaged. 
Table 1. Composition of the investigated experimental resin composites.

\begin{tabular}{|c|c|c|c|c|c|}
\hline \multirow{2}{*}{ Composite } & \multicolumn{4}{|c|}{ Resin Composition (wt\%) } & \multirow{2}{*}{ Replacement $(\%)=\left(\frac{C}{B+C}\right) \times 100$} \\
\hline & UDMA & TEGDMA & BisGMA (B) & dCl-BisGMA (C) & \\
\hline UTBC0 & 20 & 60 & 20 & 0 & 0 \\
\hline UTBC25 & 20 & 60 & 15 & 5 & 25 \\
\hline UTBC50 & 20 & 60 & 10 & 10 & 50 \\
\hline UTBC100 & 20 & 60 & 0 & 20 & 100 \\
\hline
\end{tabular}

Each composite contained fixed amounts of the filler $35 \mathrm{wt} \%$ (silanated-Aerosil 200, SA200) and the initiation system (0.2 camphorquinone (CQ) and $0.8 \mathrm{wt} \%$ 2-(N,N-dimethylamino)ethyl methacrylate (DMAEMA) with respect to the total monomers). Abbreviations: BisGMA, bisphenol A-glycidyl methacrylate; dCl-BisGMA, dichloro-BisGMA; TEGDMA, triethylene glycol dimethacrylate; UDMA, urethane dimethacrylate; UTBC0-UTBC100, composites in which BisGMA amount was replaced by $0.0-100 \%$ of dCl-BisGMA.

\subsubsection{Degree of Conversion}

The degree of DC of UTBCs due to photo-irradiation was determined using the Fourier transform infrared-attenuated total reflection (FTIR-ATR) method. Samples were pressed in stainless-steel disks ( $5 \mathrm{~mm}$ diameter and $2 \mathrm{~mm}$ thickness, $n=4)$, and their FTIR spectra were recorded (denoted as uncured) using a Nicolet iS10 FTIR spectrometer (Thermo Scientific, Madison, WI, USA). Subsequently, the specimens were covered with plastic strips and glass slides, irradiated for $40 \mathrm{~s}$ using a light-curing unit (3M ESPE Elipar S10, LED curing light; wavelength of $430-480 \mathrm{~nm}$; the intensity of approximately $1200 \mathrm{~mW} \cdot \mathrm{cm}^{-2}$ ), and then their FTIR spectra were analyzed (cured). By comparison of the peak areas of vinylic $C=C$ at $1638 \mathrm{~cm}^{-1}$ before and after curing with respect to the unaffected aromatic $\mathrm{C}=\mathrm{C}$ band at $1608 \mathrm{~cm}^{-1}$ as an internal reference, the $\mathrm{DC}$ can be quantified, as in Equation (1). Generally, the FTIR peak integration (the area, A) is proportional to its mole fraction in the spectra and, when bonds are of the same properties, their mole ratios can be adequately compared.

$$
\operatorname{DC}(\%)=\left[1-\frac{\left(\frac{A_{1638}}{A_{1608}}\right)_{\text {cured }}}{\left(\frac{A_{1638}}{A_{1608}}\right)_{\text {uncured }}}\right] \times 100
$$

\subsubsection{Water Sorption and Water Solubility}

To assess the swelling behavior of the prepared composites in oral fluid, which resulted in water sorption $\left(\mathrm{W}_{\mathrm{SP}}\right)$ and water solubility $\left(\mathrm{W}_{\mathrm{SL}}\right)$, experiments were conducted in distilled water to simulate the oral environment and in accordance with ISO 4049 [21]. The specimens were cast in fabricated stainless-steel disk-shaped molds that were $15 \mathrm{~mm}$ in diameter and with $2 \mathrm{~mm}$ thickness $(n=5)$. They were photo-irradiated from both sides in four overlapped areas for $40 \mathrm{~s}$ each. After disk preparations, samples were put in a dry silica-containing desiccator at $37^{\circ} \mathrm{C} \pm 1{ }^{\circ} \mathrm{C}$ and weighed with a Mettler Toledo analytical balance with an accuracy of $0.1 \mathrm{mg}$ every $24 \mathrm{~h}$. Prior to each recording, samples were cooled in a new desiccator at room temperature for around $1 \mathrm{~h}$. Drying-weighing processes were repeated until a constant weight was obtained (dry specimen, $\left.m_{1}\right)$. Specimens were then transferred into a $30 \mathrm{~mL}$ closed vial containing $15 \mathrm{~mL}$ distilled water and maintained at $37^{\circ} \mathrm{C} \pm 1{ }^{\circ} \mathrm{C}$. Every $24 \mathrm{~h}$, samples were removed from the water, carefully swabbed, waved in air for $20 \mathrm{~s}$, weighed, and returned to the water; this process was repeated until no change in the disk weight was observed (swelled specimen, $m_{2}$ ). Finally, disks were removed from the water and dried again as above until a constant weight was obtained $\left(m_{3}\right)$. The $\mathrm{W}_{\mathrm{SP}}$ and $\mathrm{W}_{\mathrm{SL}}$ can be calculated as in Equations (2) and (3), respectively.

$$
\begin{aligned}
& W_{S P}(\%)=\left(\frac{m_{2}-m_{1}}{m_{1}}\right) \times 100 \\
& W_{S L}(\%)=\left(\frac{m_{1}-m_{3}}{m_{1}}\right) \times 100
\end{aligned}
$$




\subsection{Statistical Analysis}

Data were analyzed using SPSS 21. Variables were presented as the mean \pm standard deviation (SD). Analysis of variance and repeated-measures analysis of variance were used to compare four groups and three cycles with Bonferroni correction as post hoc test. A $p$-value of $<0.05$ was considered significant.

\section{Results and Discussion}

\section{1. dCl-BisGMA Properties}

The chemical structure of the monomer under investigation, dCl-BisGMA, was reported elsewhere [2]. The substitution generally occurs through a catalytic Appel reaction with an $S_{N} 2$ mechanism, resulting in an inverted configuration [15,22,23] (Figure 1). AlOdayni et al. [2] reported some of the monomer physicochemical properties, including viscosity and biocompatibility. Viscosity was found to be 126-fold lower than that of BisGMA at $22.1^{\circ} \mathrm{C}$ (i.e., 909.9 and 7.2 Pa.s for BisGMA and dCl-BisGMA, respectively). The dClBisGMA biocompatibility was also evaluated within resin mixtures of TEGDMA/BisGMA against immortalized human bone marrow stromal cells, using dCl-BisGMA-free resin as a reference. In this study, dCl-BisGMA was incorporated in experimental dental composites. Then, the composite physicochemical properties, including complex viscosity, DC, $\mathrm{W}_{\mathrm{SP}}$, $\mathrm{W}_{\mathrm{SL}}$, were investigated.<smiles>C=C(C)C(=O)OC[C@H](O)COc1ccc(C(C)(C)c2ccc(OC[C@@H](O)COC(=O)C(=C)C)cc2)cc1</smiles>

Figure 1. Synthesis of the dCl-BisGMA monomer.

\subsection{Rheological Properties of UTBC Composites}

Figure 2 shows the complex viscosity $\left(\eta^{*}, \mathrm{kPa} \cdot \mathrm{s}\right)$ of the tested composites as a function of the frequency $(\omega, \mathrm{rad} / \mathrm{s})$, and Table 2 presents its evolution at $1.0 \mathrm{rad} / \mathrm{s}$. It is obvious that all the tested model composites were viscoelastic, non-Newtonian materials and showed a shear-thinning behavior, i.e., as the shear rate increased, the $\eta^{*}$ value decreased dramatically. Through the series of UTBCs, the $\eta^{*}$ value decreased, whereas the amount of dCl-BisGMA increased. The shear-thinning behavior with a frequency increase was most likely due to rearrangement of the filler particles [24]. Furthermore, shearing may also cause disentanglement of matrix molecules, particularly at a higher applied force [25], thus weakening the physical interaction between the components leading to an increase in the flowability of the composite. Generally, the viscosity of a resin composite is influenced by the type and amount of both the organic matrix and the reinforcing inorganic materials, as well as the surrounding conditions, including temperature. Since the preparation 
analysis conditions of all the tested composites were similar, except for the amount of BisGMA/dCl-BisGMA, the $\eta^{*}$ variation is due to the respective chemical properties of each of these two monomers. When dCl-BisGMA increases, $\eta^{*}$ decreases. This was predominantly due to the low viscosity of dCl-BisGMA $(\eta=7.2 \mathrm{~Pa} \cdot \mathrm{s})$, compared with that of BisGMA ( $\eta=910 \mathrm{~Pa} \cdot s)$, which is the property that is reflected in the $\eta^{*}$ values of the studied experimental composites.

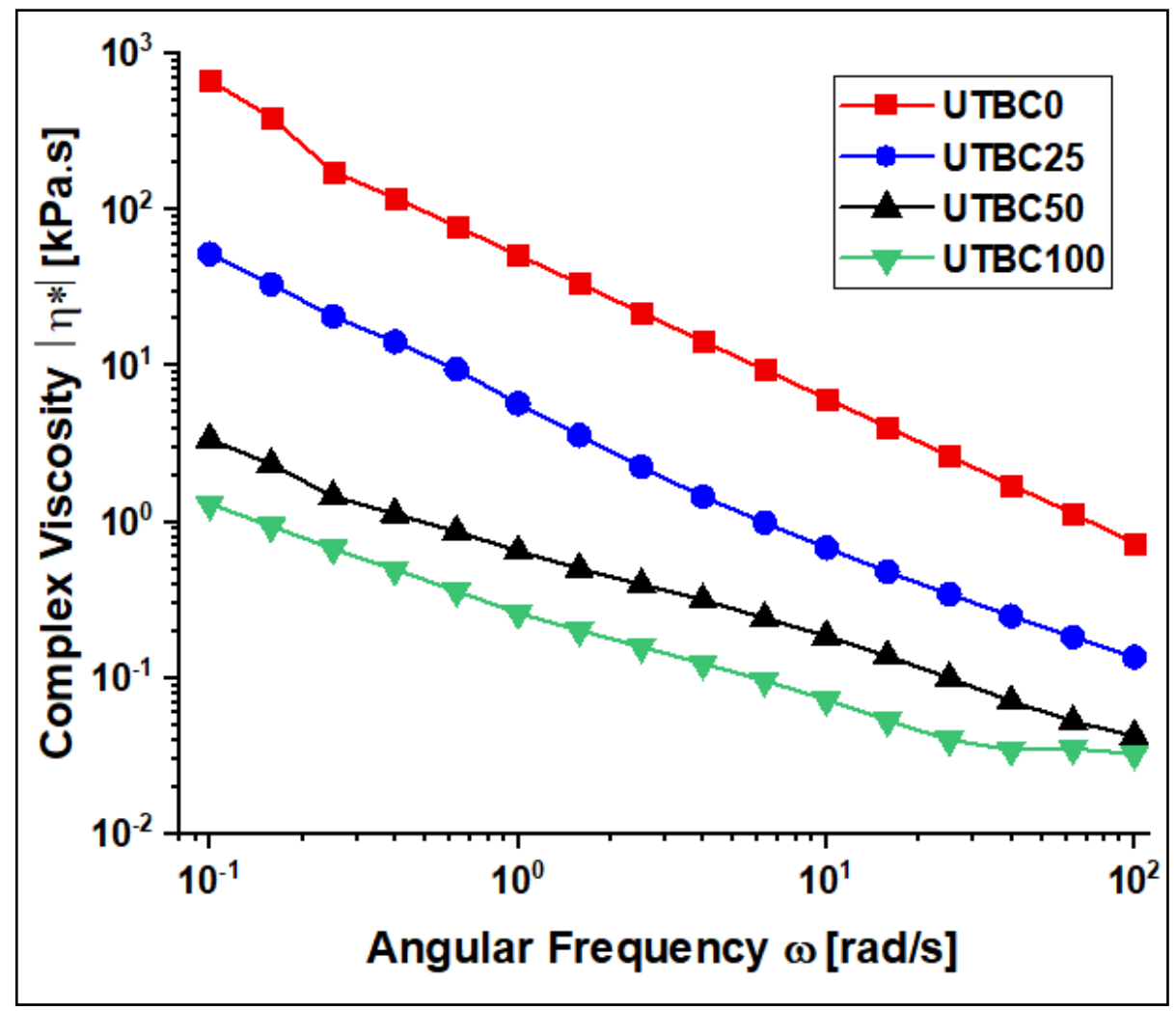

Figure 2. The complex viscosity $\left(\eta^{*}\right)$ of the $\mathrm{UTBC}$ resin composites at $25^{\circ} \mathrm{C}$.

Table 2. Degree of conversion (DC), complex viscosity $\left(\eta^{*}\right.$, at $\left.25^{\circ} \mathrm{C}\right)$, water sorption $\left(\mathrm{W}_{\mathrm{SP}}\right)$, and solubility $\left(\mathrm{W}_{\mathrm{SL}}\right)$ measured over three cycles of sorption-desorption.

\begin{tabular}{|c|c|c|c|c|c|c|c|c|}
\hline \multirow{2}{*}{ Composite } & \multirow{2}{*}{$\mathrm{DC}(\%)(n=4)$} & \multirow{2}{*}{$\begin{array}{l}\text { Complex Viscosity } \\
(\mathrm{kPa} \cdot \mathrm{s}) ; \text { at } \omega=1.0 \\
(\mathrm{rad} / \mathrm{s}),(n=4)\end{array}$} & \multicolumn{3}{|c|}{$\mathrm{W}_{\mathrm{SP}}(\mathrm{wt} / \mathrm{wt}) \%(n=5)$} & \multicolumn{3}{|c|}{$\mathrm{W}_{\mathrm{SL}}(w t / w t) \%(n=5)$} \\
\hline & & & 1st Cycle & 2nd Cycle & 3rd Cycle & 1st Cycle & 2nd Cycle & 3rd Cycle \\
\hline UTBC0 & $74.18(2.87)^{\mathrm{a}}$ & $47.29(5.92)^{\mathrm{a}}$ & $2.58(0.10)^{a, b, A}$ & $3.19(0.03)^{a, b, b}$ & $3.32(0.13)^{a, b, c}$ & $0.78(0.05)^{\mathrm{a}, \mathrm{A}}$ & $0.23(0.07)^{a, B}$ & $0.04(0.02)^{a, c}$ \\
\hline UTBC25 & $75.27(4.77)^{\mathrm{a}}$ & $5.36(0.55)^{b}$ & $2.26(0.11)^{\mathrm{a}, \mathrm{A}}$ & $2.93(0.11)^{a, B}$ & $3.14(0.02)^{a, c}$ & $0.85(0.14)^{\mathrm{b}, \mathrm{A}}$ & $0.22(0.02)^{b, B}$ & $0.07(0.07)^{\mathrm{b}, \mathrm{C}}$ \\
\hline UTBC50 & $77.36(5.02)^{a}$ & $0.63(0.07)^{b}$ & $2.11(0.47)^{\mathrm{a}, \mathrm{A}}$ & $2.76(0.05)^{a, b}$ & $2.94(0.08)^{a, C}$ & $0.82(0.41)^{\mathrm{c}, \mathrm{A}}$ & $0.19(0.05)^{\mathrm{c}, \mathrm{B}}$ & $0.04(0.06)^{c, C}$ \\
\hline UTBC100 & $79.01(4.61)^{\mathrm{a}}$ & $0.30(0.05)^{b}$ & $1.88(0.50)^{a, c, c, A, D}$ & $2.31(0.85)^{a, c, B}$ & $2.04(0.85)^{a, c, A, D}$ & $0.90(0.10)^{\mathrm{d}, \mathrm{A}}$ & $0.17(0.04)^{d, B}$ & $0.12(0.12) d, C$ \\
\hline
\end{tabular}

Within each column, the different lowercase letter is assigned to results with significant differences at $p<0.05$. Within each row, the different uppercase letter over the three cycles of both the $\mathrm{W}_{\mathrm{SP}}$ and $\mathrm{W}_{\mathrm{SL}}$ is assigned to results with significant differences at $p<0.05$. The data are presented as mean and standard deviation (SD).

The structure-property relationships of the monomers, including the symmetricity, hydrophobicity-hydrophilicity, and H-bonding, was reflected in the viscosity value of the composites [26]. A previous study reported that the viscosity of BisGMA reduces when the $-\mathrm{OH}$ functional group is replaced by chlorine in dCl-BisGMA [2]. The low viscosity of dCl-BisGMA was due to the absence of the $-\mathrm{OH}$ groups and reduced $\mathrm{H}$-bonding that is largely responsible for the strong intermolecular interactions. For instance, the complex viscosity $\left(\eta^{*}\right)$ values were decreased from 47.29 to $0.30(\mathrm{kPa} \cdot \mathrm{s})$ for dCl-BisGMAfree (UTBC0) and BisGMA-free (UTBC100) samples, respectively. Indeed, the reduced viscosity of the samples containing dCl-BisGMA in the prepared model composites was 
also reflected in the other properties, including the $\mathrm{DC}$, water uptake $\left(\mathrm{W}_{\mathrm{SP}}\right)$, and water solubility $\left(\mathrm{W}_{\mathrm{SL}}\right)$.

Figure 3 illustrates the storage $\left(G^{\prime}\right)$ and loss $\left(G^{\prime \prime}\right)$ moduli of the composites under investigation. In all the cases and at any frequency, the value of $G^{\prime}$ is greater than that of $G^{\prime \prime}$ of the same composite, reflecting that the elastic nature is prevailing and composites are stable even at higher frequency [19]. It is well known that $G^{\prime}$ and $G^{\prime \prime}$ are very sensitive to the variation in the molecular structure of matrix resins and the structural network of the composite $[27,28]$. The decrease in the moduli values with the dCl-BisGMA increase may imply there is less interaction between the components, reflecting the effect of the resin type. As the hydrophilicity of the matrix decreases with the addition of dCl-BisGMA, the physical interaction caused by H-bonding decreased, and thus, the elasticity increased. Matrices containing BisGMA are more tightly and closely packed than dCl-BisGMA-containing ones, i.e., $G^{\prime}$ is higher for UTBC0 than for the others. Moreover, the results indicated frequency-dependent moduli of UTBC50 and UTBC100, i.e., $G^{\prime}$ and $G^{\prime \prime}$ increased with frequency and increased in the whole sweeping frequency range, revealing less structural networking when the dCl-BisGMA amount exceeded that of BisGMA [29].

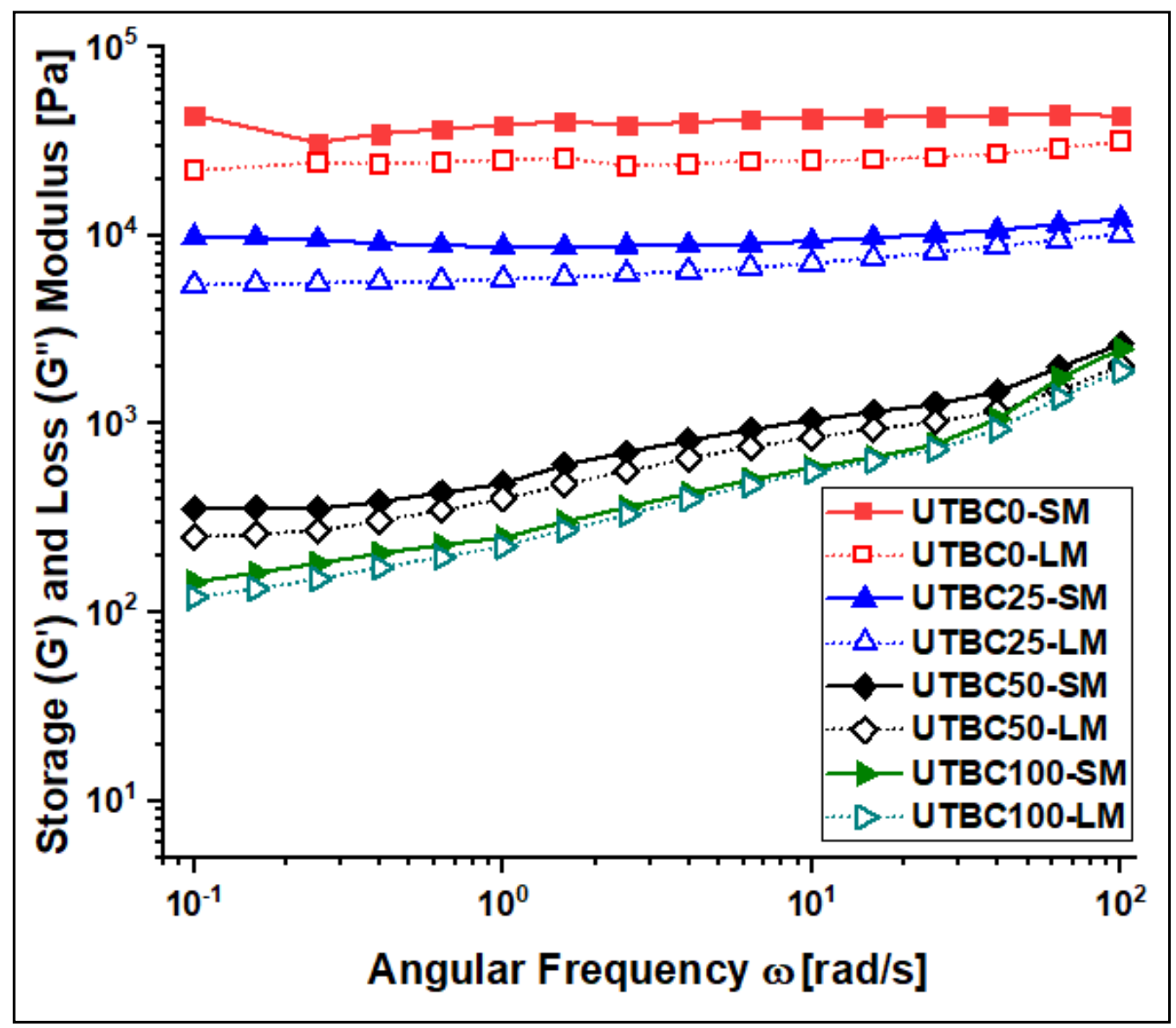

Figure 3. Storage modulus ( $\mathrm{G}^{\prime}$, solid markers) and loss modulus ( $\mathrm{G}^{\prime \prime}$, open markers) of UTBC resin composites at $25^{\circ} \mathrm{C}$.

\subsection{Analysis}

The DC of UTBCs due to photo-irradiation was assessed using FTIR. The peak area of the aliphatic curable vinyl group at about $1638 \mathrm{~cm}^{-1}\left(\mathrm{~A}_{1638}\right)$ was compared with that of the internal standard aromatic $\mathrm{C}=\mathrm{C}$ peak $\left(\mathrm{A}_{1608}\right)$ before and after light curing (Equation (1)). The results of DC measurements were reported as the average and standard deviation (SD) of four independent replicates of each resin composite (Figure 4 and Table 2). The DC was higher for composites containing dCl-BisGMA than for the reference dCl-BisGMA-free 
one. However, the difference was statistically insignificant. The slight increases in DC of dCl-BisGMA to $79.01 \%$ for UTBC100, compared with $74.18 \%$ of UTBC0, is likely due to the lower viscosity of dCl-BisGMA, allowing better mobility of the particles (molecules and radicals) and thus facilitating higher conversion. Generally, incomplete vinylic DC is due to rapid solidification and gelation that may hamper radical mobility. Since the experimental conditions are the same, and dCl-BisGMA has a structure similar to that of BisGMA, except for the secondary hydroxyl groups, the altered properties of UTBC100 could be attributed to the absence of $-\mathrm{OH}$ and the presence of $-\mathrm{Cl}$. Furthermore, dClBisGMA allows enhancement of the hydrophobicity characteristic and thus reduced the intermolecular interaction, leading to lower viscosity compared to BisGMA. According to literature [30-32], many factors can influence the DC of composites, including resin matrix composition, filler type and geometry, and their ratios and curing conditions. The effect of filler loading and degree of salinization on the DC has also been investigated [30], reporting lower conversion with increasing filler percentage but no visible differences between the DC of silane treated and untreated fillers, whereas DC decreases with silane amount increase. Compared with filled composites, the DC of the unfilled resin matrix is higher due to mobility restriction caused by fillers [33]. This negative impact of filler on the DC is independent of whether or not the filler was silanized [30]. In this regard, the DC of unfilled composites containing dCl-BisGMA was found to increase with dCl-BisGMA amount increase [2]. For instance, the DC of resins containing $70 \mathrm{wt} \%$ of BisGMA or dClBisGMA (and $30 \mathrm{wt} \%$ TEGDMA) were 62.0 and $70.6 \%$, respectively, which is reasonably due to the lower viscosity of dCl-BisGMA, compared with that of BisGMA. In this study, the DC of UTBCs was in the range of $74.18-79.01 \%$ and increased with dCl-BisGMA amount increased. However, the apparent higher values of DC of UTBCs are due to the high amount used of diluents TEGDMA and UDMA (50\% and 30\% with respect to the total resin weight, respectively). Generally, the percentage of DC for adequate clinical performance has not yet been determined [34]. Nevertheless, for both filled and unfilled dCl-BisGMA-based composites, the obtained DC was above the minimum acceptable values for clinical use (>55\%) [35]. The DC of dental composite commonly varies between $40 \%$ and $75 \%$ [36]; however, other ranges were also reported [37,38] with higher values closer to $85 \%$ [39]. The difference in the DC of various systems can be due to several reasons, including the variation in composition, viscosity, curing conditions, curing times, etc. In this work, the resin matrix of UTBC0 consists of conventional monomers (TEGDMA, TEGDMA, and BisGMA) commonly used in dental composites. Thus, this dCl-BisGMAfree composite was used as a control during the evaluation of the tested properties of dCl-BisGMA containing composites (UTBC25-UTBC100).

\subsection{Water Sorption and Solubility}

The effect of replacing BisGMA by dCl-BisGMA on water uptake $\left(\mathrm{W}_{\mathrm{SP}}\right)$ and solubility $\left(\mathrm{W}_{\mathrm{SL}}\right)$ of resin-based dental composites was also investigated. The results are given as a percentage with respect to disk weight ((wt/wt)\%; three cycles). As given in Table 2, the $\mathrm{W}_{\text {SP }}$ of UTBC100 was significantly different from that of UTBC $0(p<0.05)$, indicating great enhancement, even for the three cycles of the sorption-desorption process. However, a significant increase over the three cycles for both the control (UTBC0) and samples (UTBC25 to UTBC100) was observed, apparently due to void generation as a result of soluble materials exclusion. It is clear that increasing dCl-BisGMA decreases $W_{S P}$ but increases $\mathrm{W}_{\mathrm{SL}}$. The value of $\mathrm{W}_{\mathrm{SP}}$ is generally associated with $\mathrm{DC}$ and the network structure, specifically the hydrophilicity-hydrophobicity characteristics, three-dimensional structure, and free volume [40]. Here, $\mathrm{W}_{\mathrm{SP}}$ decreased with increasing DC, as expected, owing to the low hydrophilicity of dCl-BisGMA. 


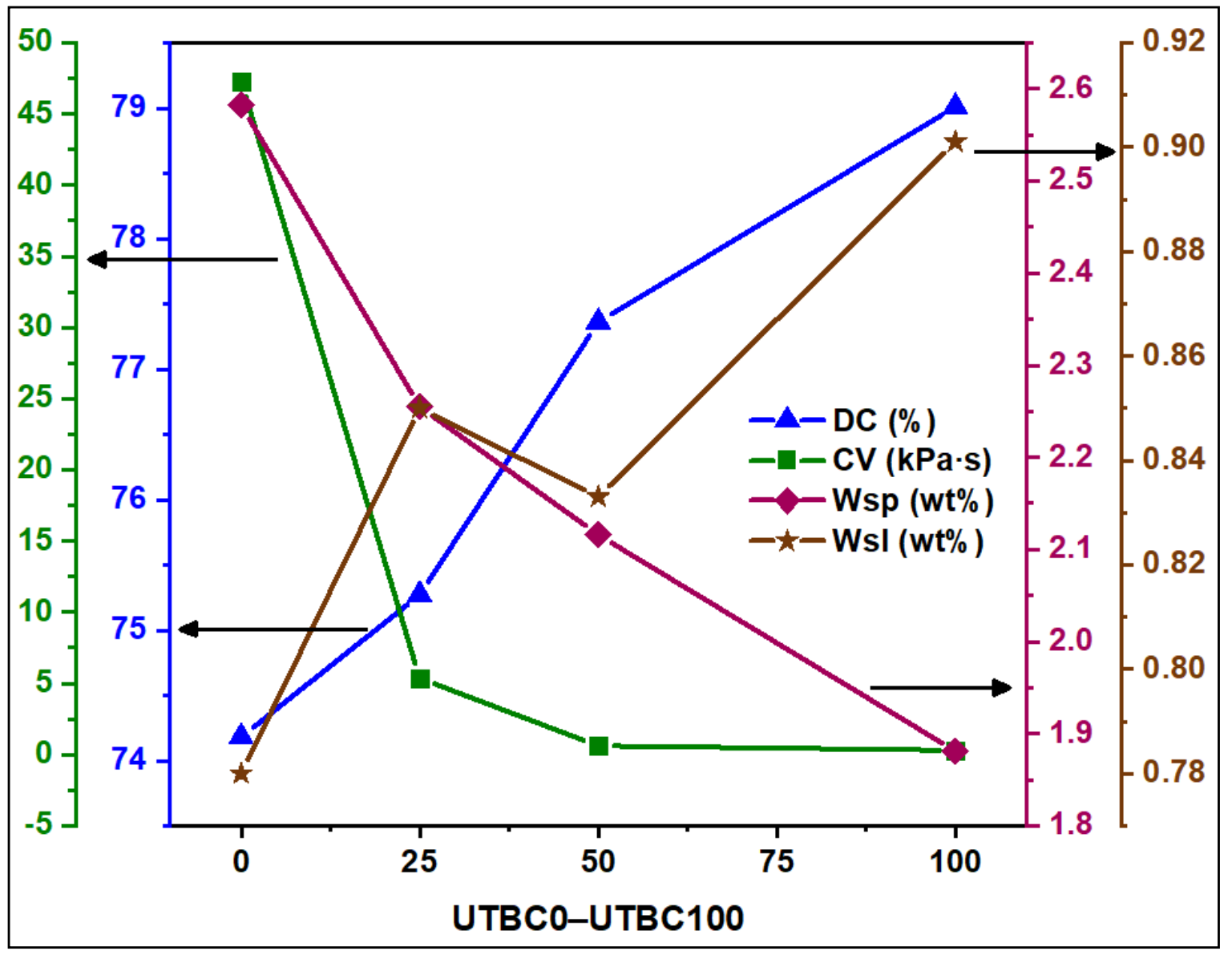

Figure 4. Degree of conversion (DC), complex viscosity $(\mathrm{CV})$ at $1.0 \mathrm{rad} / \mathrm{s}$ angular frequency, water uptake $\left(\mathrm{W}_{\mathrm{SP}}\right)$, and water solubility $\left(\mathrm{W}_{\mathrm{SL}}\right)$ of the first cycle of sorption-desorption versus the dCl-BisGMA amount in the investigated composites (UTBC0, UTBC25, UTBC50, and UTBC100).

Conversely, although $\mathrm{W}_{\mathrm{SL}}$ increased with the $\mathrm{dCl}$-amount increase, $\mathrm{W}_{\mathrm{SP}}$ decreased. However, $\mathrm{W}_{\mathrm{SL}}$ depended on both the amount of water absorbed and the amount and hydrophilicity of the leachable materials, as well as the microstructure of the polymeric network. A previous study on the effects of dimethacrylate monomer hydrophilicity reported that the hydrophobic monomers are more flexible than hydrophilic ones and contribute to a higher free volume in the polymeric network, despite the value of DC. Moreover, flexible monomers tend to undergo primary and secondary cyclization, which may cause gelation, forming short chains, and leachable species (monomers and oligomers) that contribute to the increased solubility of the final composite [41]. Thus, the increase in $\mathrm{W}_{\mathrm{SL}}$ with increasing dCl-BisGMA concentrations, despite increasing $\mathrm{W}_{\mathrm{SP}}$ and $\mathrm{DC}$, may be attributed to the formation of small fragments upon polymerization as a result of the cyclization of more flexible monomers (i.e., dCl-BisGMA and TEGDMA) [40]. This was further supported by the lower $\mathrm{W}_{\mathrm{SL}}$ for UTBC0, compared with that for UTBC100, despite the lower DC and $\mathrm{W}_{\mathrm{SP}}$ values. The $\mathrm{W}_{\mathrm{SP}}$ and $\mathrm{W}_{\mathrm{SL}}$ behavior, evaluated after three cycles of the sorption-desorption process, as shown in Table 2 and Figure 5, revealed a slight increase in $W_{S P}$ and decrease in $W_{S L}$ from cycle 1 to cycle 3 . However, $W_{S L}$ decreased to near zero after cycle 2, indicating that the release of leachable species ceased. The values of $\mathrm{W}_{\mathrm{SP}}$ and $\mathrm{W}_{\mathrm{SL}}$ may also be influenced by filler size in the composite. In this regard, previous studies highlighted higher $\mathrm{W}_{\mathrm{SP}}$ and $\mathrm{W}_{\mathrm{SL}}$ of nanocomposites compared with hybrid ones [42,43]. This behavior could be explained on the basis of the high surface area of the nanofillers, making them more prone to ion leaching and hydrolysis of the silane coupling agent. 

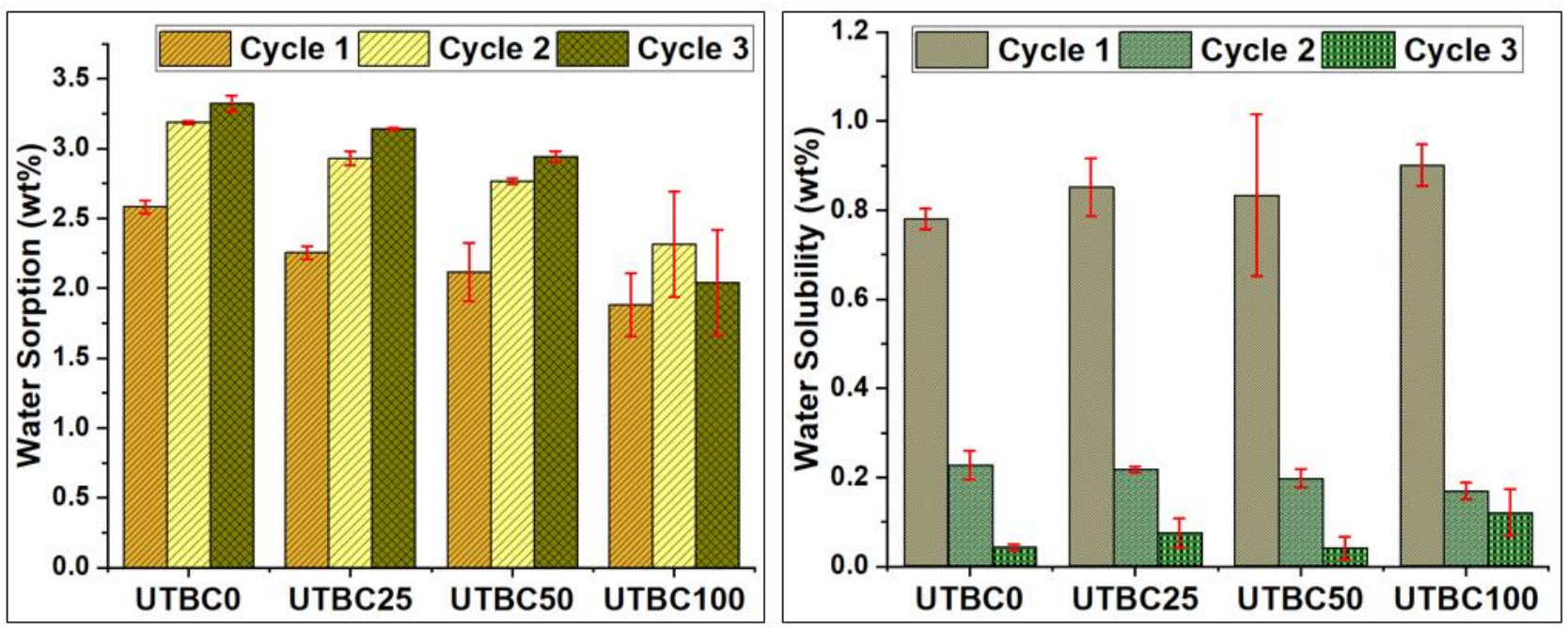

Figure 5. Water upatake and water solubility of UTBC0-UTBC100 after three cycles of sorption-desorption processes.

\section{Conclusions}

Low-viscosity BisGMA derivatives are of great importance and could offer solutions to the disadvantage associated with its high viscosity toward property enhancement of the current resin-based dental composites. The present study was designed to evaluate the advantage of replacing BisGMA, owing to its low viscosity and low hydrophilicity, with an analog dCl-BisGMA monomer in resin-based dental composites. The study confirmed that $\mathrm{dCl}$-BisGMA is a promising alternative monomer for BisGMA. The relevant supporting properties including complex viscosity, $\mathrm{DC}$, and $\mathrm{W}_{\mathrm{SP}}$ were enhanced when BisGMA is replaced, even partially, by dCl-BisGMA in the matrix. The rheological investigations revealed a pseudoplastic, non-Newtonian, and shear thinning behavior, demonstrating a disproportional decrease in complex viscosity with increasing frequency at $25^{\circ} \mathrm{C}$. At all frequencies, the complex viscosity of composites containing dCl-BisGMA was significantly lower than the control (UTBC0). DC showed a slight, statically insignificant increase with the increase of dCl-BisGMA, e.g., from 74.18 \pm 2.87 to $79.01 \pm 4.61$ for UTBC0 and UTBC100, respectively. The $\mathrm{W}_{\mathrm{SP}}$ was significantly enhanced, reduced almost to half when BisGMA was totally replaced by dCl-BisGMA (i.e., from $2.58 \%$ to $1.88 \%$, respectively); however, an increase in the $W_{S L}$ values was observed, which is due to the cyclization process that occurred on the microstructure level as a result of the differences in the hydrophilicity of the polymeric matrix, which decreases as dCl-BisGMA increases. The overall findings will be of interest for the development of resin-based composites for various applications including dental materials, providing insight for future composite property enhancements. Therefore, this new material deserves further investigation for complete characterization as a potential matrix.

Author Contributions: Conceptualization, A.-B.A.-O. and A.A.; data curation, A.-B.A.-O.; formal analysis, A.-B.A.-O., R.K. and W.S.S.; funding acquisition, A.A.; investigation, A.-B.A.-O., R.K. and K.A.; methodology, A.-B.A.-O. and T.A.; project administration, A.A. and A.A.-K.; supervision, A.A. and A.A.-K.; visualization, A.-B.A.-O. and W.S.S.; writing-original draft preparation, A.-B.A.-O.; writing - review and editing, A.-B.A.-O. All authors have read and agreed to the published version of the manuscript.

Funding: This research received no external funding.

Data Availability Statement: The authors confirm that the data supporting the findings of this study are available within the article.

Acknowledgments: The authors are grateful to the Deanship of Scientific Research, King Saud University, for funding through the Vice Deanship of Scientific Research Chairs, Engineer Abdullah Bugshan research chair for Dental and Oral Rehabilitation. 
Conflicts of Interest: The authors declare no conflict of interest.

\section{References}

1. Pratap, B.; Gupta, R.K.; Bhardwaj, B.; Nag, M. Resin based restorative dental materials: Characteristics and future perspectives. Jpn. Dent. Sci. Rev. 2019, 55, 126-138. [CrossRef] [PubMed]

2. Al-Odayni, A.-B.; Alfotawi, R.; Khan, R.; Saeed, W.S.; Al-Kahtani, A.; Aouak, T.; Alrahlah, A. Synthesis of chemically modified BisGMA analog with low viscosity and potential physical and biological properties for dental resin composite. Dent. Mater. 2019, 35, 1532-1544. [CrossRef]

3. Khatri, C.A.; Stansbury, J.W.; Schultheisz, C.R.; Antonucci, J.M. Synthesis, characterization and evaluation of urethane derivatives of Bis-GMA. Dent. Mater. 2003, 19, 584-588. [CrossRef]

4. Peutzfeldt, A. Resin composites in dentistry: The monomer systems. Eur. J. Oral Sci. 1997, 105, 97-116. [CrossRef] [PubMed]

5. Podgórski, M. Synthesis and characterization of novel dimethacrylates of different chain lengths as possible dental resins. Dent. Mater. 2010, 26, e188-e194. [CrossRef] [PubMed]

6. Kim, J.; Kim, L.; Kim, C.; Cho, B.; Kim, O. Characteristics of novel dental composites containing 2, 2-bis [4-(2-methoxy-3methacryloyloxy propoxy) phenyl] propane as a base resin. Biomacromolecules 2006, 7, 154-160. [CrossRef] [PubMed]

7. Buruiana, T.; Melinte, V.; Jitaru, F.; Aldea, H.; Buruiana, E.C. Photopolymerization experiments and properties of some urethane/urea methacrylates tested in dental composites. J. Compos. Mater. 2012, 46, 371-382. [CrossRef]

8. Melinte, V.; Buruiana, T.; Chibac, A.; Mares, M.; Aldea, H.; Buruiana, E.C. New acid BisGMA analogs for dental adhesive applications with antimicrobial activity. Dent. Mater. 2016, 32, e314-e326. [CrossRef]

9. Rivera-Torres, F.; Vera-Graziano, R. Effects of water on the long-term properties of Bis-GMA and silylated-(Bis-GMA) polymers. J. Appl. Polym. Sci. 2008, 107, 1169-1178. [CrossRef]

10. Wang, R.; Zhu, M.; Bao, S.; Liu, F.; Jiang, X.; Zhu, M. Synthesis of two Bis-GMA derivates with different size substituents as potential monomer to reduce the polymerization shrinkage of dental restorative composites. J. Mater. Sci. Res. 2013, 2, 12. [CrossRef]

11. Jeon, M.; Yoo, S.; Kim, J.; Kim, C.; Cho, B. Dental restorative composites fabricated from a novel organic matrix without an additional diluent. Biomacromolecules 2007, 8, 2571-2575. [CrossRef] [PubMed]

12. Srivastava, R.; Wolska, J.; Walkowiak-Kulikowska, J.; Koroniak, H.; Sun, Y. Fluorinated bis-GMA as potential monomers for dental restorative composite materials. Eur. Polym. J. 2017, 90, 334-343. [CrossRef]

13. Al-Odayni, A.-B.; Saeed, W.S.; Ahmed, A.Y.B.H.; Alrahlah, A.; Al-Kahtani, A.; Aouak, T. New Monomer Based on Eugenol Methacrylate, Synthesis, Polymerization and Copolymerization with Methyl Methacrylate-Characterization and Thermal Properties. Polymers 2020, 12, 160. [CrossRef] [PubMed]

14. Pereira, S.G.; Osorio, R.; Toledano, M.; Cabrerizo-Vílchez, M.A.; Nunes, T.G.; Kalachandra, S. Novel light-cured resins and composites with improved physicochemical properties. Dent. Mater. 2007, 23, 1189-1198. [CrossRef]

15. Alrahlah, A.; Al-Odayni, A.-B.; Al-Mutairi, H.F.; Almousa, B.M.; Alsubaie, F.S.; Khan, R.; Saeed, W.S. A Low-Viscosity BisGMA Derivative for Resin Composites: Synthesis, Characterization, and Evaluation of Its Rheological Properties. Materials 2021, 14, 338. [CrossRef] [PubMed]

16. Atai, M.; Pahlavan, A.; Moin, N. Nano-porous thermally sintered nano silica as novel fillers for dental composites. Dent. Mater. 2012, 28, 133-145. [CrossRef] [PubMed]

17. Kleczewska, J.; Bieliński, D.; Nowak, J.; Sokołowski, J.; Łukomska-Szymańska, M. Dental composites based on dimethacrylate resins reinforced by nanoparticulate silica. Polym. Polym. Compos. 2016, 24, 411-418. [CrossRef]

18. Zanchi, C.H.; Ogliari, F.A.; e Silva, R.M.; Lund, R.G.; Machado, H.H.; Prati, C.; Carreño, N.L.V.; Piva, E. Effect of the silane concentration on the selected properties of an experimental microfilled composite resin. Appl. Adhes. Sci. 2015, 3, 27. [CrossRef]

19. Alrahlah, A.; Khan, R.; Al-Odayni, A.-B.; Saeed, W.S.; Bautista, L.S.; Vohra, F. Evaluation of Synergic Potential of rGO/SiO2 as Hybrid Filler for BisGMA/TEGDMA Dental Composites. Polymers 2020, 12, 3025. [CrossRef] [PubMed]

20. Rostamzadeh, P.; Mirabedini, S.M.; Esfandeh, M. APS-silane modification of silica nanoparticles: Effect of treatment's variables on the grafting content and colloidal stability of the nanoparticles. J. Coat. Technol. Res. 2014, 11, 651-660. [CrossRef]

21. Standards, I. ISO 4049 Dentistry-Polymer based restorative materials. Int. Organ. Stand. 2009, 4, 1-28.

22. Appel, R. Tertiary Phosphane/Tetrachloromethane, a Versatile Reagent for Chlorination, Dehydration, and P N Linkage. Angez. Chem. Int. Ed. Engl. 1975, 14, 801-811. [CrossRef]

23. Castro, B.R. Replacement of alcoholic hydroxyl groups by halogens and other nucleophiles via oxyphosphonium intermediates. Org. React. 2004, 29, 1-162.

24. Meier, R.; Kirdar, C.; Rudolph, N.; Zaremba, S.; Drechsler, K. Investigation of the shear thinning behavior of epoxy resins for utilization in vibration assisted liquid composite molding processes. In AIP Conference Proceedings; American Institute of Physics: College Park, MD, USA, 2014; pp. 458-462.

25. Vlachopoulos, J.; Strutt, D. The Role of Rheology in Polymer Extrusion. In Proceedings of the New Technology for Extrusion Conference; pp. 20-21.

26. Lee, I.-B.; Son, H.-H.; Um, C.-M. Rheologic properties of flowable, conventional hybrid, and condensable composite resins. Dent. Mater. 2003, 19, 298-307. [CrossRef] 
27. Haddadi, H.; Famili, M.H.N.; Nazokdast, E.; Moradi, S. Chemorheological analyses of a reaction injection moulding polyurethane formulation. Iran. Polym. J. 2006, 15, 967-977.

28. Kumar, S.; Zindani, D.; Bhowmik, S. Investigation of mechanical and viscoelastic properties of flax-and ramie-reinforced green composites for orthopedic implants. J. Mater. Eng. Perform. 2020, 29, 3161-3171. [CrossRef]

29. Zhu, J.; Wei, S.; Yadav, A.; Guo, Z. Rheological behaviors and electrical conductivity of epoxy resin nanocomposites suspended with in-situ stabilized carbon nanofibers. Polymer 2010, 51, 2643-2651. [CrossRef]

30. Halvorson, R.H.; Erickson, R.L.; Davidson, C.L. The effect of filler and silane content on conversion of resin-based composite. Dent. Mater. 2003, 19, 327-333. [CrossRef]

31. Turssi, C.; Ferracane, J.; Vogel, K. Filler features and their effects on wear and degree of conversion of particulate dental resin composites. Biomaterials 2005, 26, 4932-4937. [CrossRef]

32. Rastelli, A.N.; Jacomassi, D.P.; Faloni, A.P.S.; Queiroz, T.P.; Rojas, S.S.; Bernardi, M.I.B.; Bagnato, V.S.; Hernandes, A.C. The filler content of the dental composite resins and their influence on different properties. Microsc. Res. Tech. 2012, 75, 758-765. [CrossRef]

33. Bociong, K.; Szczesio, A.; Krasowski, M.; Sokolowski, J. The influence of filler amount on selected properties of new experimental resin dental composite. Open Chem. 2018, 16, 905-911. [CrossRef]

34. Lempel, E.; Czibulya, Z.; Kovács, B.; Szalma, J.; Tóth, Á.; Kunsági-Máté, S.; Varga, Z.; Böddi, K. Degree of conversion and BisGMA, TEGDMA, UDMA elution from flowable bulk fill composites. Int. J. Mol. Sci. 2016, 17, 732. [CrossRef] [PubMed]

35. Silikas, N.; Eliades, G.; Watts, D. Light intensity effects on resin-composite degree of conversion and shrinkage strain. Dent. Mater. 2000, 16, 292-296. [CrossRef]

36. Moldovan, M.; Balazsi, R.; Soanca, A.; Roman, A.; Sarosi, C.; Prodan, D.; Vlassa, M.; Cojocaru, I.; Saceleanu, V.; Cristescu, I. Evaluation of the degree of conversion, residual monomers and mechanical properties of some light-cured dental resin composites. Materials 2019, 12, 2109. [CrossRef] [PubMed]

37. Galvão, M.R.; Caldas, S.G.F.R.; Bagnato, V.S.; de Souza Rastelli, A.N.; de Andrade, M.F. Evaluation of degree of conversion and hardness of dental composites photo-activated with different light guide tips. Eur. J. Dent. 2013, 7, 86. [PubMed]

38. Pałka, K.; Kleczewska, J.; Sasimowski, E.; Belcarz, A.; Przekora, A. Improved Fracture Toughness and Conversion Degree of Resin-Based Dental Composites after Modification with Liquid Rubber. Materials 2020, 13, 2704. [CrossRef]

39. Kowalska, A.; Sokolowski, J.; Bociong, K. The Photoinitiators Used in Resin Based Dental Composite-A Review and Future Perspectives. Polymers 2021, 13, 470. [CrossRef]

40. Pfeifer, C.S.; Shelton, Z.R.; Braga, R.R.; Windmoller, D.; Machado, J.C.; Stansbury, J.W. Characterization of dimethacrylate polymeric networks: A study of the crosslinked structure formed by monomers used in dental composites. Eur. Polym. J. 2011, 47, 162-170. [CrossRef] [PubMed]

41. Young, J.S.; Kannurpatti, A.R.; Bowman, C.N. Effect of comonomer concentration and functionality on photopolymerization rates, mechanical properties and heterogeneity of the polymer. Macromol. Chem. Phys. 1998, 199, 1043-1049. [CrossRef]

42. Silva, E.M.d.; Almeida, G.S.; Poskus, L.T.; Guimarães, J.G.A. Relationship between the degree of conversion, solubility and salivary sorption of a hybrid and a nanofilled resin composite. J. Appl. Oral Sci. 2008, 16, 161-166. [CrossRef] [PubMed]

43. Kumar, N.; Sangi, L. Water sorption, solubility, and resultant change in strength among three resin-based dental composites. J. Investig. Clin. Dent. 2014, 5, 144-150. [CrossRef] [PubMed] 